\title{
Presença de anticorpo anti-Lutheran $B$ em paciente com leucemia linfóide aguda
}

\section{Anti-Lutheran B in a patient with acute lymphoblastic leukemia}

Maria do Rosário F. Roberti ${ }^{1}$

Cristiane A. Tuma

Janeslane F. Maciel $^{3}$
Leucemias agudas necessitam de suporte hemoterápico para serem tratadas adequadamente. A presença do anticorpo anti-Lutheran B e a alta freqüência do antígeno em nossa população dificulta o tratamento de doenças hematológicas que necessitam de suporte transfusional, tais como a leucemia linfóide aguda (LLA). Alternativas de tratamento hemoterápico são abordadas neste artigo. Descreve-se o caso de uma paciente com LLA e anticorpo anti-Lutheran B. A dificuldade em encontrar sangue compatível levou os autores a adotarem estratégia conservadora no tratamento hemoterápico. $O$ uso de eritropoetina e a adoção de protocolo quimioterápico individualizado viabilizaram os resultados obtidos. Rev. bras. hematol. hemoter. 2007; 29(2):189-192.

Palavras-chave:Leucemia aguda de células B; sistema do grupo sangüíneo Lutheran; eritropetina recombinante; incompatibilidade de grupos sangüíneos; transfusão de sangue.

\section{Introdução}

O antígeno Lutheran B está presente em cerca de 99,76\% da população brasileira. ${ }^{1}$ Pacientes que apresentam anticorpos contra antígenos de alta freqüência populacional são um problema para a medicina transfusional. ${ }^{2}$ Descreve-se o caso de uma paciente com diagnóstico de leucemia linfóide aguda com a presença de anti-Lutheran B e as dificuldades e soluções encontradas para a condução do caso em uma cidade do Centro-Oeste do país.

\section{Relato de caso}

Mulher branca de 27 anos, com duas gestações prévias, sem relato de doença hemolítica do recém-nascido (DHRN), com diagnóstico de leucemia linfóide aguda (LLA) desde 05/1999. Iniciou o quadro com cansaço e dor óssea, tendo recebido uma unidade de concentrado de hemácias (CH), a uma semana do diagnóstico. Não apresentava si- nais de hemólise na admissão e a hemoglobina $(\mathrm{Hb})$ era de $84 \mathrm{~g} / \mathrm{L}$. Recebeu como tratamento o protocolo BFM-87³ (Tabela 1) e no D15 do tratamento apresentava $\mathrm{Hb}: 74 \mathrm{~g} / \mathrm{L}$, plaquetas 32 x $10^{9} / \mathrm{L}$ e leucócitos $1,1 \times 10^{9} / \mathrm{L}$. O grupo sangüíneo era $\mathrm{O}, \mathrm{CDE}$ negativo e os testes pré-transfusionais demonstraram a presença de anticorpos irregulares, antiLutheran B (anti-Lu ${ }^{\mathrm{b}}$ ) e anti-D. Iniciou uso de eritropoetina alfa recombinante (EPO), 5000U/dia, três vezes por semana e transfusão de plaquetas randômicas, $6 \mathrm{U} / \mathrm{m}^{2}$, com objetivo de manter plaquetas acima de $50 \times 10^{9} / \mathrm{L}$. Não apresentou reação hemolítica, apesar de receber plaquetas contaminadas com hemácias em algumas das transfusões. No D22 da quimioterapia de indução apresentava pancitopenia intensa, com níveis de Hb: 48 g/L, mesmo em uso regular da EPO. As drogas mielotóxicas foram suspensas nos D15 e D22. No D28 o mielograma de controle mostrava remissão completa. A partir desta data não recebeu qualquer tipo de transfusão. Iniciou a fase 2 da reindução com doses de citosina e ciclofosfamida reduzidas em $50 \%$, sem EPO. A fase de

${ }^{1}$ Doutora em Clínica Médica pela Universidade de São Paulo. Professora da disciplina Práticas Integradoras da

Universidade Federal de Goiás - UFG. Médica hematologista do Hospital Geral de Goiânia - HGG.

${ }^{2}$ Médica hematologista da Universidade de Goiás - UFG.

${ }^{3}$ Biomédica do Hospital Araújo Jorge. Coordenadora do Comitê de Ética Médica da Santa Casa de Misericórdia de Goiânia.

Correspondência: Maria do Rosário F. Roberti

Rua L, $n^{\circ} .53$ apto 501, Setor Oeste

74120-050 - Goiânia-GO - Brasil

Tel.: 062-3229-0004 - Fax: 062-3229-0004

E-mail: família.roberti@ig.com.br 
Tabela 1 - Resumo do protocolo BFM $87^{3}$ aplicado na paciente

\begin{tabular}{|c|c|c|c|}
\hline \multicolumn{4}{|c|}{ Indução } \\
\hline Droga & Dose & Via & Dias \\
\hline \multicolumn{4}{|l|}{ Fase 1} \\
\hline Prednisona & $60 \mathrm{mg} / \mathrm{m}^{2}$ & VO & D1 - 28 \\
\hline Vincristina & $2 \mathrm{mg}$ & EV & D $1,8,15,22$ \\
\hline Daunorrubicina & $45 \mathrm{mg} / \mathrm{m}^{2}$ & EV & D $1,8,15,22$ \\
\hline L-Asparaginase & $5000 \mathrm{U} / \mathrm{m}^{2}$ & EV & D $15-28$ \\
\hline Methotrexate & $12 \mathrm{mg}$ & IT & D 1 \\
\hline \multicolumn{4}{|l|}{ Fase 2} \\
\hline Ciclofosfamida & $650 \mathrm{mg} / \mathrm{m}^{2}$ & $\mathrm{EV}$ & D 29 e 57 \\
\hline Citarabina & $75 \mathrm{mg} / \mathrm{m}^{2}$ & EV & $\begin{array}{c}\text { D } 31-34 ; 38-41 ; \\
45-48 ; 52-55\end{array}$ \\
\hline 6 Mercaptopurina & $60 \mathrm{mg} / \mathrm{m}^{2}$ & VO & D $29-57$ \\
\hline Methotrexate & $15 \mathrm{mg}$ & $\Pi$ & D $31,38,45,52$ \\
\hline \multicolumn{4}{|c|}{ Manutenção } \\
\hline 6 Mercaptopurina & $60 \mathrm{mg} / \mathrm{m}^{2}$ & VO & $\begin{array}{c}\text { Diariamente, } \\
\text { semana } 28-132\end{array}$ \\
\hline Methotrexate & $20 \mathrm{mg} / \mathrm{m}^{2}$ & $\mathrm{IM}$ & Semana 28 - 132 \\
\hline Methotrexate & $15 \mathrm{mg}$ & $\Pi$ & A cada 2 meses, \\
\hline Citarabina & $40 \mathrm{mg}$ & $\Pi$ & num total de \\
\hline Dexametasona & $4 \mathrm{mg}$ & $\Pi$ & 12 aplicações \\
\hline
\end{tabular}

consolidação não foi realizada devido à necessidade de utilizar quimioterapia em altas doses. Na fase de manutenção, doses plenas de quimioterápicos foram empregadas até a semana 132, quando foi suspensa a quimioterapia (outubro/ 2001). Permaneceu em remissão completa por 23 meses, quando apresentou células blásticas em sangue periférico e 99\% de linfoblastos ao mielograma, sendo diagnosticada a recaída da doença. Nesta data, a hemoglobina era 149 g/L. Foram coletadas duas bolsas de sangue autólogo, que foram utilizadas durante o $1^{\circ}$ e $2^{\circ}$ ciclos de $\mathrm{HCVAD}^{4}$ (Tabela 2).

A busca de sangue compatível no estado de Goiás e em outros estados foi realizada sem sucesso. A paciente foi tratada com o protocolo HCVAD com doses plenas de quimioterapia e não recebeu EPO desta vez, devido a problemas relativos à aquisição da droga. Nesta data, os testes prétransfusionais demonstraram a presença de anti-D e os títulos de anti-Lu $u^{\mathrm{b}}$ foram indetectáveis. A partir do $3^{\circ}$ ciclo de quimioterapia, as doses de citosina foram reduzidas a $50 \%$. Recebeu, no total, seis dos oito ciclos propostos pelo protocolo. A manutenção foi iniciada precocemente devido à mielotoxicidade e à falta de hemoderivados compatíveis. A paciente encontra-se em remissão completa, com sobrevida global de 81 meses. Recebeu as seguintes transfusões: 63 unidades de plaquetas heterólogas e duas unidades de concentrado de hemácias autólogas. Todos os familiares (pais, irmãos e primos próximos) apresentavam o fenótipo Lutheran B. A paciente não possui doador HLA-compatível. Nas fases de mielotoxicidade, a paciente recebeu estrógenos conjugados como profilaxia de sangramento genital.
Tabela 2. Resumo do protocolo $\mathrm{HCVAD}^{4}$ aplicado na paciente

\begin{tabular}{cccc}
\hline \multicolumn{4}{c}{ Ciclos 1, 3 e 5 } \\
\hline Droga & Dose & Via & Dias \\
\hline Ciclofosfamida & $300 \mathrm{mg} / \mathrm{m}^{2}$ & EV 12/12 h & D1,D2,D3 \\
Vincristina & $2 \mathrm{mg}$ & EV & D4 e D11 \\
Doxorrubicina & $50 \mathrm{mg} / \mathrm{m}^{2}$ & EV & D4 \\
Dexametasona & $40 \mathrm{mg}$ & VO & D1,D2,D3,D4 \\
Methotrexato & $12 \mathrm{mg}$ & $\Pi$ & D2 e D7 \\
Citarabina & $100 \mathrm{mg}$ & $\pi$ & D2 e D7 \\
\hline \multicolumn{4}{c}{ Ciclos 2, 4 e 6 } \\
Methotrexato & $1 \mathrm{~g} / \mathrm{m}^{2}$ & EV em 24h & \\
infusão contínua & D1 \\
Methotrabina & $3 \mathrm{~g} / \mathrm{m}^{2}$ & EV 12/12 h & D2 e D3 \\
Citarabina & $12 \mathrm{mg}$ & $\pi$ & D2 e D7 \\
\hline
\end{tabular}

\section{Discussão}

Os grupos sangüíneos humanos foram descobertos há mais de cem anos. No decorrer do século 20, diferentes terminologias foram utilizadas para descrevê-los. A partir de 1980, a Sociedade Internacional de Transfusão de Sangue (ISBT) estabeleceu uma terminologia numérica baseada nos caracteres genéticos de cada antígeno de superfície dos grupos sangüíneos, os quais vêm sendo atualizados periodicamente. $^{5}$

Os antígenos protéicos do sistema de grupos sangüíneos Lutheran são glicoproteínas integrais de membrana, do tipo I, presentes na membrana celular como dois isômeros. Estes são produtos de um único gene, LU, localizado no cromossomo 19q13.2. O sistema de grupos sangüíneos Lutheran consiste de 18 antígenos sorologicamente documentados, numerados de LU1 a LU20, sendo os de número LU10 e LU15 obsoletos. Quatro pares de antígenos LU1/LU2 (Lu//Lu $)$, LU6/LU19, LU8/LU14 e LU18/LU19 (Auª/Au') são alelos e polimórficos e os dez remanescentes são antígenos de altíssima freqüência. ${ }^{6}$

O antígeno Lutheran B está presente em cerca de 99,76\% da população brasileira, não havendo diferença estatística entre caucasóides, mulatos e negros. ${ }^{1}$ Devido à alta freqüência do antígeno na população, estima-se que em cada quinhentas bolsas de sangue, uma será compatível. ${ }^{2}$

A transfusão de sangue raro é infreqüente. Quando necessária, a cooperação internacional pode assegurar que o sangue compatível esteja disponível para estes pacientes específicos. ${ }^{7}$ Os bancos de sangue nos países desenvolvidos possuem uma estratégia para a busca de sangue raro. ${ }^{8}$ A ISBT desenvolveu um procedimento para operacionalizar este processo. ${ }^{7}$ A prevalência de doenças infecciosas difere ao redor do mundo. Devido às diferentes exigências existentes de um país para outro, o sangue doado em um país 
pode não ser adequado para transfusão em outro, sendo necessários testes sorológicos adicionais no país onde será realizada a transfusão. ${ }^{7}$ Os custos referentes à busca, ao transporte e à transfusão são de responsabilidade do país receptor. Portanto, a provisão de sangue raro torna-se um desafio, já que é alto o custo da busca, estoque e transporte deste hemoderivado. ${ }^{8}$ No estado de Goiás não há este tipo de suporte hemoterápico. Quando há solicitação de sangue raro, os doadores que forem compatíveis são catalogados e convocados quando necessário. Infelizmente, esta estratégia atende à minoria dos pacientes, já que o número de doadores é pequeno e o processo não é 100\% informatizado, dificultando a cooperação entre os bancos de sangue locais, além da falta de conscientização do doador. Na ausência de doador Lu $u^{\mathrm{b}}$ negativo em Goiânia, optou-se por acionar outros bancos de sangue fora do estado. Todavia, a busca foi infrutífera, devido à alta freqüência populacional do antígeno Lutheran B. ${ }^{1}$

A associação de anemia clinicamente significativa e câncer é freqüente, seja devido à própria doença de base, secundária ao tratamento empregado ou à anemia de doença crônica. ${ }^{9}$ Historicamente, transfusões de $\mathrm{CH}$ eram realizadas visando a concentração de hemoglobina acima de 10,0 g/dL o que garantiria bom aporte de oxigênio aos tecidos. Atualmente, muitos autores recomendam transfusão de $\mathrm{CH}$ nos pacientes com concentração de hemoglobina inferior a 7,0 g/dL, mantendo transfusões com valores de hemoglobina superiores a 10,0 g/dL somente em casos excepcionais. ${ }^{10,11,12}$ Componentes contendo hemácias não devem ser utilizados para tratar anemias que podem ser corrigidas com medicações específicas. ${ }^{13}$ A utilização do nível de hemoglobina como parâmetro isolado para a indicação de transfusões vem sendo contestada. A avaliação clínica baseada nos sinais vitais, condições hemodinâmicas e presença de sangramento ativo associados aos valores de hemoglobina devem ser utilizados como parâmetros para a indicação do uso de hemoderivados. ${ }^{12,14}$

O uso clínico de EPO em portadores de tumores sólidos e malignidades hematológicas não mielóides mostra um aumento nas concentrações de hemoglobina, redução das necessidades transfusionais e melhora na qualidade de vida, embora o benefício na sobrevida não seja documentado. ${ }^{15,16}$ Quirt e cols estudaram o uso de EPO alfa em portadores de câncer, em uso ou não de quimioterapia. As malignidades hematológicas, exceto leucemias agudas, foram incluídas no estudo, tendo os autores concluído que o uso da EPO melhora a qualidade de vida e diminui as necessidades transfusionais, embora este dado não tenha sido estatisticamente significante. ${ }^{9}$ A paciente recebeu EPO no primeiro tratamento, pois era a única estratégia que poderia eventualmente permitir o aumento da $\mathrm{Hb}$ já que não foram encontradas hemácias compatíveis. Não foi possível avaliar a resposta ao uso da EPO, pois a paciente recebeu aproximadamente quatro semanas de tratamento com um terço da dose preconiza- da na literatura ${ }^{16,17}$ e logo a seguir atingiu remissão completa. O tratamento de pacientes críticos sem a utilização de sangue e hemoderivados é um tópico de interesse para estudo. Algumas destas situações clínicas peculiares incluem: recusa por parte do paciente em receber hemoderivados (em geral testemunhas de Jeová), sangue compatível não avaliável (presença de múltiplos anticorpos irregulares ou de auto-anticorpos) ou pequeno suprimento de hemoderivados. Algumas estratégias de tratamento são adotadas nestes pacientes, em geral, uso de sangue autólogo, controle do sangramento, quando presente, e restrição da coleta de sangue para testes laboratoriais. Nos casos oncológicos, a terapia proposta é o uso de EPO associado a protocolos individualizados de tratamento, minimizando a toxicidade hematológica, com profilaxia farmacológica e tratamento do sangramento. ${ }^{13}$

O protocolo HCVAD, que utiliza altas doses de quimioterápicos, ${ }^{4}$ requer suporte transfusional para a maioria dos pacientes. A impossibilidade de oferecê-lo por quaisquer razões praticamente inviabiliza o sucesso do tratamento. $\mathrm{Na}$ primeira indução utilizaram-se plaquetas randômicas compatíveis e redução nas doses das drogas mielotóxicas, objetivando minimizar o sangramento. Na indução da recaída, a ausência de bolsas compatíveis foi suprida parcialmente pela transfusão autóloga, apesar do número limitado de bolsas. Neste caso, a estratégia adotada foi a preconizada por Goodnough e cols, a qual sugere a adoção de um protocolo individualizado, profilaxia com estrógenos conjugados para prevenir o sangramento menstrual e transfusão de plaquetas profiláticas, mantendo-as acima de $50 \times 10^{9} / \mathrm{L} .^{13} \mathrm{O}$ uso de hemácias autólogas também contribuiu para a manutenção de níveis de hemoglobina seguros. Nas leucemias agudas, esta recomendação pode ser dificultada, pois a maioria dos pacientes abre o quadro com anemia sintomática. A EPO não foi utilizada na recaída, devido à dificuldade na aquisição da mesma.

Após o diagnóstico, a paciente não recebeu hemácias heterólogas. Há relato na literatura de paciente portadora de neoplasia metastática de mama com a presença de anti- $\mathrm{Lu}^{\mathrm{b}}$, em tratamento oncológico, que recebeu duas unidades de $\mathrm{CH}$ sem apresentar hemólise imediata ou tardia. ${ }^{18} \mathrm{Tal}$ fato nos faz pensar que talvez os testes in vitro, para este tipo em particular de anticorpo, tenham maior significado do que in vivo.

Tratar pacientes com anticorpos dirigidos a antígenos de alta frequiência populacional requer busca incessante por doadores compatíveis, na qual se torna de grande valia o cadastro de doadores de sangue raro nos bancos de sangue. Uma rede de cadastro nacional facilitaria a busca em nosso país, porém o alto custo deste processo muitas vezes inviabiliza a transfusão.

A indicação de transfusão de $\mathrm{CH}$ em pacientes com concentração de hemoglobina entre 7,0 e 10,0 g/dL reduz em até $50 \%$ as necessidades transfusionais, quando comparada 
às indicações visando valores usados historicamente. ${ }^{11} \mathrm{~Pa}$ cientes com a presença de anticorpos de alta freqüência populacional se beneficiariam desta estratégia.

O conhecimento das técnicas para tratamento de anemia sem a utilização de hemoderivados faz-se mandatória, uma vez que em torno de $15 \%$ das transfusões indicadas para pacientes com anticorpos dirigidos a antígenos de alta freqüência populacional não serão atendidas. ${ }^{8}$

A pronta aplicação de drogas que estimulam a eritropoese e a utilização de protocolos individualizados exercem papel fundamental na condução destes casos e na sobrevida destes pacientes.

\begin{abstract}
Acute leukemia needs hemotherapeutic support to be successfully treated. The Lutheran B antibody, specifically the high frequency of this antigen in our population, has made it difficult to treat hematological malignancies that need transfusional support, including acute lymphoblastic leukemia. Finding compatible blood is complex and so the authors adopted a conservative treatment strategy. The prescription of epoetin and an individualized chemotherapy protocol may improve results. We describe a case report of a patient with anti-Lutheran B antibody and how difficulties to find compatible blood were solved. Rev. bras. hematol. hemoter. 2007;29(2):189-192.
\end{abstract}

Key words: Leukemia; B-cell; acute; Lutheran Blood-Group System; erythropoietin; recombinant; blood group incompatibility; blood transfusion.

\section{Referências Bibliográficas}

1. Novaretti MCZ, Dorlhiac-Llacer PE, Chamone DAF. Estudo de grupos sangüíneos em doadores de sangue caucasóides e negróides na cidade de São Paulo. Rev Bras Hematol Hemoter. 2000;22:23-32.

2. Reid ME, Oyen R, Marsh WL. Summary of the clinical significance of blood group alloantibodies. Semin Hematol. 2000;37:197-216.

3. Ludwig W-D, Rieder H, Bartram CR, Heinze B, Schwartz S, Gassmann $\mathrm{W}$, et al. Immunophenotypic and genotype features, clinical characteristics, and treatment outcome of adult pro-B acute lymphoblastic leukemia: Results of the German multicenter trials GMALL 03/87 and 04/89. Blood. 1998;92:1898-909.

4. Koller CA, Kantarjian HM, Thomas D, O'Brien S, Rios MB, Kornblau $\mathrm{S}$, et al. The Hyper-CVAD regimen improves outcome in relapsed acute lymphocytic leukemia. Leukemia. 1997;11:2039-44.

5. Daniels GL, Fletcher A, Garratty G, Henry S, Jorgensen J, Judd WJ, et al. Blood group terminology 2004: from the international society of blood transfusion committee on terminology for red cell surface antigens. Vox Sang. 2004;87:304-16.

6. Crew VK, Green C, Daniels G. Molecular bases of the antigens of the Lutheran blood group system. Transfusion. 2003;43:1729-37.

7. Anstee D, Levene C, Mallory D, Overbeeke M, Poole J, Reid M, et al. Rare Blood. An ISBT working party report on rare blood donors. Vox Sang. 1999;77:58-62.

8. Seltsam A, Wagner FF, Salama A, Flegel WA. Antibodies to highfrequency antigens may decrease the quality of transfusion support: an observational study. Transfusion. 2003;43:1563-6.
9. Quirt I, Robeson C, Lau CY, Kovacs M, Burdette-Radoux S, Dolan $\mathrm{S}$, et al. Epoetin alpha therapy increases hemoglobin levels and improves quality of life in patients with cancer-related anemia who are not receiving chemotherapy and patients with anemia who are receiving chemotherapy. J Clin Oncol. 2001;19:4126-34

10. Walsh TS, Garrioch M, Maciver C. Red cell requirements for intensive care units adhering to evidence-based transfusion guidelines. Transfusion. 2004;44(10):1405-11.

11. Hebert PC, Wells G, Blajchman MA, Marshal J, Marshal C, Pagliarello G, et al. A multicenter, randomized, controlled clinical trial of transfusion requirements in critical care. N Engl J Med. 1999;340(6):409-17.

12. Murphy MF, Wallington TB, Kelsey P, Boulton F, Bruce M, Cohen $\mathrm{H}$, et al. Guidelines for the clinical use of red cell transfusions. $\mathrm{Br}$ J Haematol. 2001;113(1):24-31.

13. Goodnough LT, Shander A, Spence R. Bloodless medicine: clinical care without allogeneic blood transfusion. Transfusion. 2003;43: 668-76.

14. Ferreira JS, Ferreira VLPC, Pelandré GL. Transfusão de concentrado de hemácias em Unidade de Terapia intensiva. Rev Bras Hematol Hemoter. 2005;27(3):179-82

15. Littlewood T, Collins G. Epoetin alfa: basic biology and clinical utility in cancer patients. Expert Rev Anticancer Ther. 2005;5 (6):947-56

16. Aapro M, Bajetta E, Freund M, Littlewood TJ, Nortier JWR, Rapoport B. Is there a possible survival benefit to increasing hemoglobin levels with epoetin alpha during chemotherapy? Eur J Cancer. 2004;2(2):20-28

17. Goodnough LT, Lawrence T, Monk TG, Andriole GL. Erytropoietin therapy. N Engl J Med. 1997;336(13):933-38.

18. Yahalom V, Ellis MH, Poole J, Rahimi-Levene N, Shinar E, DaCosta Y, et al. The rare Lu:-6 phenotype in Israel and the clinical significance of anti-Lu6. Transfusion. 2002;42:247-50.

Avaliação: Editor e dois revisores externos

Conflito de interesse: não declarado

Recebido: 08/05/2006

Aceito: 04/12/2006 